\title{
Article \\ Crowdsourcing Local Knowledge with PPGIS and Social Media for Urban Planning to Reveal Intangible Cultural Heritage
}

\author{
Pilvi Nummi \\ Department of Built Environment, Aalto University, 02150 Espoo, Finland; E-Mail: pilvi.nummi@aalto.fi
}

Submitted: 15 November 2017 | Accepted: 13 March 2018 | Published: 29 March 2018

\begin{abstract}
In participatory urban planning, understanding local stakeholders' viewpoints is central, and, thus, gathering local knowledge has become a frequent task in planning practice. However, the built cultural heritage is usually evaluated by experts neglecting the values and opinions of citizens. In this study, a crowdsourcing model for assessing local residents' viewpoints and values related to the built cultural heritage of Nikkilä was developed. The aim was to find out if crowdsourcing with public participation GIS and social media is a functional method for revealing local people's values, place-based memories and experiences. In the case study, non-professional knowledge was compared with expert knowledge and valuable knowledge about the intangible aspects of the built cultural heritage was reached through place-based memories. Apart from that, social media provided visual representations of place-based experiences and a tool for building a collective memory. Based on the results, it is evident that a multi-method crowdsourcing model can be a functional model for crowdsourcing local knowledge. However, there are several challenges in analysing data and using the knowledge in urban planning.
\end{abstract}

\section{Keywords}

crowdsourcing; cultural heritage; place-based memories; PPGIS; social media; urban planning

\section{Issue}

This article is part of the issue "Crowdsourced Data and Social Media for Participatory Urban Planning", edited by Bernd Resch (University of Salzburg, Austria), Peter Zeile (Karlsruhe Institute of Technology, Germany) and Ourania Kounadi (University of Salzburg, Austria).

(C) 2018 by the author; licensee Cogitatio (Lisbon, Portugal). This article is licensed under a Creative Commons Attribution 4.0 International License (CC BY).

\section{Introduction}

Crowdsourcing can be a powerful tool for enhancing public participation in urban planning processes (Brabham, 2009). In general, crowdsourcing can be considered as an activity of using the power of the crowd to accomplish a task or to solve a problem (Nakatsu, Grossman, $\&$ Charamblos, 2014). The concept was first introduced by Jeff Howe in Wired magazine in 2006, when he wrote about businesses outsourcing tasks to undefined groups of people (Howe, 2006).

In academic research, there are various interpretations of crowdsourcing. Recently, the concept of crowdsourcing has been used in research related to public participation GIS (PPGIS) in the meaning of gathering data with map surveys (e.g., López-Aparicio, Vogt, Schneider, Kahila-Tani, \& Broberg, 2017; Pánek \& Benediktsson,
2017) and extracting knowledge from user-generated social media data (e.g., Dunkel, 2015; Zhou \& Zhang, 2016). Contrary to this, Brabham (2009) and Seltzer and Mahmoudi (2012) argue that collecting data for planning with web-based surveys or using user-generated social media data should not be considered as crowdsourcing. They emphasise that crowdsourcing is about problem-solving and, in urban planning, crowdsourcing should include planning solutions to answer planning problems. However, based on a wider definition of crowdsourcing presented by Nakatsu et al. (2014), any task related to the job (i.e., planning) can be crowdsourced.

Nevertheless, some researchers have argued that more empirical research in close relation to real planning situations is needed to prove if crowdsourcing methods really are applicable and useful in urban planning and decision making (Nielek, Ciastek, \& Kope, 2017). 
This study fills that gap by applying a crowdsourcing method in an actual urban planning case study in Nikkilä, Sipoo, Finland.

In this study, knowledge gathering with PPGIS and social media is considered as crowdsourcing. In the case study Nikkilä Memories, a crowdsourcing model for collecting local knowledge related to people's memories, experiences and values is developed and tested in Nikkilä, Sipoo. Social media and PPGIS are used for collecting local people's place-based memories related to old buildings and places of Nikkilä. In addition to the collected data, the author uses her own experiences from urban planning practices as a source for this study.

\subsection{Introduction to the Case Study Nikkilä Memories}

Nikkilä is the administrative centre of Sipoo, a growing municipality within the metropolitan area of Helsinki, Finland. In Sipoo, there are currently 20,000 inhabitants, of which approximately 4,400 live in Nikkilä. Despite its small population size and rural character, Sipoo is at the moment one of the fastest growing municipalities in Finland with $2 \%$ annual population growth rate. The centre of Nikkilä is undergoing a transformation: the population rate will be doubled in the coming decades, and, thus, the existing structure of the centre will be densified and new housing areas will be built close to the centre. Currently, an outline plan of the whole area is in the making, to define the areas for densification and enlargement of the town. The Nikkilä Memories case study provides local knowledge, especially for the outline planning process, but also for future detailed planning of Nikkilä.

In the post-industrial cities, cultural aspects such as cultural heritage have been identified as an important resource for urban development and planning. Built cultural heritage is an evident asset when cities are aiming to create and maintain a distinctive and authentic sense of place (Bianchini \& Ghilardi, 2007). The cultural resources of Nikkilä have been studied recently (Nummi \& Tzoulas, 2015), and, based on that, built cultural heritage has been identified as a cornerstone of the identity of the place. Therefore, it is relevant to further study the values and meanings related to the cultural heritage of Nikkilä.

Furthermore, it is relevant to study and understand intangible aspects of cultural heritage. Zukin (2012) argues that 'advocates working within the framework of cities' historic preservation laws generally focus on protecting the tangible heritage of individual buildings and districts' while the intangible heritage is neglected. Historic monuments and buildings are being preserved, whereas urban places that do not possess tangible historical values are underappreciated. Hence, to reveal the intangible aspects of the cultural heritage of Nikkilä, it is relevant to understand the local culture and local stakeholders' viewpoints.

In the case study of Nikkilä, crowdsourcing is used to collect and share place-based memories and experiences to find out what the value of the built cultural heritage is and what elements form the intangible cultural heritage of Nikkilä. The idea of collecting place-based memories came together in a discussion between the author and the planners of Sipoo. The planners pointed out that there was a need to update and complete the expert inventory of the built cultural heritage as the data was inadequate for assessing the significance of old buildings. They also wanted to engage local people in the evaluation of the buildings, and, together with the author, they came up with an idea of crowdsourcing.

The novelty of this research is that it combines two complementary methods and data sources, i.e., social media and PPGIS data, in the crowdsourcing model. Apart from that, in relation to the cultural heritage, this study brings together experts and non-professional knowledge as parallel and comparable.

\section{Background}

\subsection{Participatory Urban Planning}

In the urban planning context, crowdsourcing can be seen as a model for enhancing public participation (Brabham, 2009). Planning theorists, like Patsy Healey (1997, 1999), define participatory planning as a communicative and human-centred approach to urban planning and decision making. Participatory planning is connected to deliberative democracy, a model of democracy that emphasises public debate and discussion as a basis for fair decision making. The framework of collaborative planning, presented by Healey $(1997,1999)$, is a communicative model for participatory urban planning. Healey describes planning as 'an interactive process, involving communicative work among participants, during which issues, problems, strategies and policy ideas are given form and meaning' (Healey, 1997, p. 91). She also points out that knowledge building that aims at shared understanding is a central part of a collaborative planning process (Healey, 1999). Furthermore, Healey (1997) emphasises acknowledging and accepting different types of knowledge, both expert and non-expert, into the planning process. Van Herzele (2004) describes local knowledge as non-professional knowledge expressed by participants (particularly local residents) in a planning process. Furthermore, Kahila and Kyttä (2008) argue that experiential knowledge generated by local people can be considered as local knowledge as well. Based on this, local place-based memories and experiences produced in the case study Nikkilä Memories can be seen as local knowledge.

The adoption of participatory urban planning practices in Finland has been advanced by the land use and building law that came into effect in 2000 . It is required that everyone in Finland should have the opportunity to participate in the planning processes that are affecting their everyday lives or living environment (Finlex, 1999). It is mandatory to present plan proposals publicly and 
provide citizens with a possibility to give feedback about the proposed planning solution, but it is not obligatory, for example, to engage citizens in goal setting in the beginning of the planning process or in designing planning solutions during the planning process. Despite the good intentions of the act, it has produced planning practices where participation takes place at a very late stage of planning, and the citizens' role remains narrow, an opinion giver. It is widely acknowledged that successful results require participation in an early phase of planning (Eräranta \& Staffans, 2015). In the case study of Nikkilä Memories, the crowdsourcing method is tested in an early phase of planning to answer this practical question.

\subsection{Crowdsourcing in Urban Planning Context}

The principal definition of crowdsourcing in the urban planning context is problem-solving. Both Brabham (2009) and Seltzer and Mahmoudi (2012) present models of crowdsourcing solutions for planning problems. Seltzer and Mahmoudi do not include social media, PPGIS or other survey methods in crowdsourcing. They argue that crowdsourcing should always contain ideas generation and solution selection phases, which usually do not exist in processes that focus on gathering local knowledge. Brabham (2009) describes crowdsourcing in urban planning as a tool for outsourcing the design of planning solutions. Furthermore, he argues that it is a question of empowering citizens by letting them also vet the planning solutions created by the crowd. It is worth mentioning that, according to Brabham, crowdsourcing is not a bottom-up approach to urban planning. On the contrary, it is very much a top-down steered process with a well-defined and focused task that the crowd is participating in.

In recent crowdsourcing studies, examples of local knowledge gathering and methods supporting nonexperts to design planning proposals are presented. For example, Mueller, Lu, Chirkin, Klein and Schmitt (2018) present a model and toolkit (Quick Urban Analysis Kit) for crowdsourcing citizen feedback, ideas and wishes. They developed a participatory planning strategy which combined a co-design approach with crowdsourcing methods and introduced a design tool that enables nonexperts to do simple design tasks. Examples of knowledge gathering for urban planning relate to various subjects. For example, Yang and $\mathrm{Ng}$ (2017) have tested the potential of using crowdsourced user-generated data to monitor urban rainfall. They found that crowdsourced data lead to a more accurate modelling of storm water flows as compared to rain gauge data. Pánek and Benediktsson (2017) applied an 'emotional mapping' methodology to study cyclists' opinions about cycling routes and places that they encounter in Reykjavík, Iceland. They describe their data collection method as geographical crowdsourcing, and argue that this kind of participatory planning support system can help to bridge the gap between planners and citizens. López-Aparicio et al.
(2017) used a PPGIS tool for collecting information about wood burning for residential heating in Norway, and described the method as crowdsourcing as well.

The development and research of PPGIS methods, web map tools for gathering local knowledge, have been going on for a decade (Kahila-Tani, Broberg, Kyttä, \& Tyger, 2016). Brown (2015) argues that crowdsourcing with PPGIS tools is starting to become more frequent in urban planning practices. Crowdsourcing with PPGIS tools is closely related with the concept of volunteered geographical information (VGI), which means the process of users voluntarily producing geographic data, such as marking geographic features or objects (e.g., updating OpenStreetMap) or adding geodata to objects shared in social media (Elwood, Goodchild, \& Sui, 2012). Taking into account Brabham's (2009) definition of crowdsourcing, VGI can also be considered as crowdsourcing if it is steered top-down, for example, by the municipal authorities in the case of urban planning.

On the grounds of previous definitions of crowdsourcing and examples, social media should not be considered as crowdsourcing, because the users are not accomplishing any predefined tasks or trying to solve a problem. However, in many studies that use usergenerated social media data as a data source for an analysis, this is presented as a form of crowdsourcing, as will be reported in Section 2.3. Also, a social media platform can be used for crowdsourcing if the users are contributing to a task, for example, taking part in data gathering by posting pictures on Instagram, as in the case study of Nikkilä Memories.

\subsection{Social Media Data Analysis in Urban Planning}

Using social media in knowledge gathering for urban planning is relatively new and there are few studies related to actual planning processes using social media data (Nummi, 2017). Generally, in public administration, social media tools are used for information dissemination and collaboration, and Khan (2015) argues that models for social media-based government are found useful for increasing public participation. Khan presents different relationships between citizens and government, and points out that citizens can, for example, act as an informational source via social media channels by providing feedback or expert opinion for government.

The use of social media has been increasing over the last decade and new services are being implemented. Social media have become a part of many people's everyday life: for example, in Finland, more than $50 \%$ of inhabitants have a profile in a social media channel (Official Statistics of Finland, 2017). For urban planning, this offers opportunities to communicate with citizens and to study various aspects of citizens' experiences, opinions and feelings. In other words, social media can be used as an interaction tool or a data source in urban planning.

When social media are seen as a data source, as in this study, it is relevant to contemplate social media 
data analysis methods (SMDA). These are computational methods for analysing user-generated content from social media (Nummi, 2017). Recently, in academia, there has been an increasing interest in adopting social media analysis methods for urban planning. For example, Tasse and Hong (2014) presented opportunities to use geotagged social media data to better understand cities, and a variety of SMDA methods have been studied in case studies in different parts of the world. The increasing numbers of research papers in this field suggest the topicality of this subject. These methods can be categorised in four themes: opinion mining, place-based experiences, understanding people's behaviour in a city, and the city structure based on social media data (Nummi, 2017).

For example, people's place-based experiences have been studied by Dunkel (2015), who developed a GIS method for analysing people's landscape experiences and values using crowdsourced data from Instagram. Apart from that, urban sounds and smells (Aiello, Schifanella, Quercia, \& Aletta, 2016; Quercia, Aiello, \& Schifanella, 2016), feeling of stress (Sykora et al., 2015) and emotions (Resch, Summa, Zeile, \& Strube, 2016) have been studied to help planners to understand how people experience the city. Opinion mining has been used by Campagna and colleagues (Campagna, 2014; Campagna, Floris, Massa, Girsheva, \& Ivanov, 2015), who created a special social media platform to listen to citizens' viewpoints in relation to city planning in Cagliari, Italy, and by López-Ornelas and Zaragoza (2015), who studied opinions and feelings related to a new airport in Mexico City. Points of interest (POI) are an obvious source of planningrelated data that describes crowd behaviour in a city and, thus, provide insight into places and areas that attract people (Hu et al., 2015; Paldino, Bojic, Sobolevsky, Ratti, \& González, 2015).

Analysis methods that reveal the structure of the city are often based on location-based (e.g., geotagged) social media data. For example, Frias-Martinez and FriasMartinez (2014) studied geotagged Tweets to find out the actual land use of areas based on people's activities. They were able to analyse areas that are used for business, leisure, housing and nightlife with a GIS analysis. Methods that detect similarities between areas are also enlightening the city structure from users' point of view. For example, Cranshaw, Schwartz, Hong and Sadeh (2012) developed a tool called Livehoods that visualises on a map areas that are similar based on residents' activities.

\section{Research Questions and Methods}

The overall research problem is what kind of crowdsourcing model can reveal local people's values and placebased memories related to the built cultural heritage. The need for this case study came from the urban planners of Sipoo, as they had pointed out the need to better understand the value and meaning of old buildings and places in Nikkilä for local inhabitants. An inventory of cul- tural heritage objects and areas was conducted earlier, in 2005 , by experts in built cultural heritage and architecture (Municipality of Sipoo, 2006). The weakness of such expert examination is that it does not take residents' viewpoints into account. One important question in the case study was whether the values of residents are in line with this expert evaluation or not. In participatory urban planning, identifying local people's viewpoints and values is central to be able to focus the development goals and draw alignments in a culturally and socially sustainable way.

The research questions were posed from both research and planning perspectives. The actual research questions were related to crowdsourcing model and methods:

- What kind of crowdsourcing model can be used for gathering local place-based memories, values and experiences related to the built cultural heritage?

- Is crowdsourcing a functional model for this task?

- What is the value of using social media in crowdsourcing?

- What kind of challenges and benefits does this crowdsourcing model produce?

From the urban planning perspective, the following questions are studied:

- Which old buildings are valuable to local people in Nikkilä?

- Are experts' evaluations and the values of nonprofessional people in line or do they differ?

- What does the data reveal about the intangible aspects of cultural heritage?

- How can the results from the crowdsourcing be reflected in planning?

In the case study of Nikkilä Memories, these questions are approached with a multi-method approach that combines a map questionnaire and social media data. The map questionnaire was created with the Maptionnaire tool. Social media were used to facilitate people to share their memories from Nikkilä with hashtag \#muistojennikkilä, and a local Facebook group related to old buildings in Sipoo was observed.

The aim of this case study was to examine how local people value cultural heritage objects (e.g., historical buildings and cultural landscape areas in Nikkilä) and what kind of memories they have related to the built cultural heritage. The idea behind the approach was that people's memories are related to the appreciation they feel towards the cultural heritage, and that memories can reveal the intangible cultural heritage of Nikkilä.

\section{The Case Study Nikkilä Memories}

In the following sections, the starting points, methods and data of the case study Nikkilä Memories are pre- 
sented. First, the village of Nikkilä is described, and then crowdsourcing methods (map questionnaire, social media monitoring and observation of a self-organized Facebook group) and the analysis method are presented.

\subsection{Nikkilä-A Small Town in the Centre of Sipoo, Finland}

Nikkilä is a town with currently only approximately 4,400 inhabitants. The area is undergoing major transformation, because the aim of the municipality is to more than double the population within the next 10 years. This, of course, means that the environment will change significantly, and, thus, it is important to engage local people in the planning of the area. The case study of Nikkilä Memories is part of an ongoing participatory process started a few years ago (Nummi \& Tzoulas, 2015).

The areal image of Nikkilä (Figure 1) describes the physical characteristics of the village. The dense centre of Nikkilä is surrounded by rural agricultural areas, fields and forests. In the foreground of the picture, a new housing area of Sipoon Jokilaakso (the River Valley of Sipoo) is under construction. Apart from these expansion areas, the existing structure of Nikkilä is being densified. Old department and office buildings from the 1980s have been pulled down and replaced by new apartment buildings in the centre of Nikkilä (Figure 2, above).

The history of Nikkilä derives from the mediaeval age. An old mediaeval stone church (Figure 2 ) built in the fifteenth century is the oldest building in Nikkilä. The built cultural heritage is diverse; along the main street, Iso Kylätie, there are several old wooden buildings from the late nineteenth or early twentieth century (Figure 2). In the twentieth century, development of the village was strongly affected by the establishment of a mental hospital in 1914. The hospital operated in Nikkilä until 1999, and, after it was closed, the hospital area was renovated to a picturesque housing area, but still the termination of the hospital decreased the population and liveability of Nikkilä.

\subsection{Crowdsourcing Model}

The elementary idea of the crowdsourcing project was to set the expert-driven cultural heritage inventory under public evaluation with a map questionnaire. Apart from that, people's place-based memories and experiences were crowdsourced. A map questionnaire was developed with a PPGIS tool called Maptionnaire, and it was used in parallel with social media to offer multiple ways for people to express their thoughts. In social media, people were encouraged to share their memories from Nikkilä with the hashtag \#muistojennikkilä. Both of these methods are explained in detail in the next sections.

\subsection{Map Questionnaire}

The map questionnaire was open from 21 March-31 July 2016 and 186 answers were received. The data consisted of more than 700 evaluations of old buildings, 39 written memories, 12 images and 106 markings for personally important buildings. The questionnaire was an open web questionnaire and, thus, the data is biased towards those participants who are most interested in the local built cultural heritage of Nikkilä. This kind of methodology can be considered as a crowdsourcing data collection (not as a survey method) as the sample of respondents is not representative.

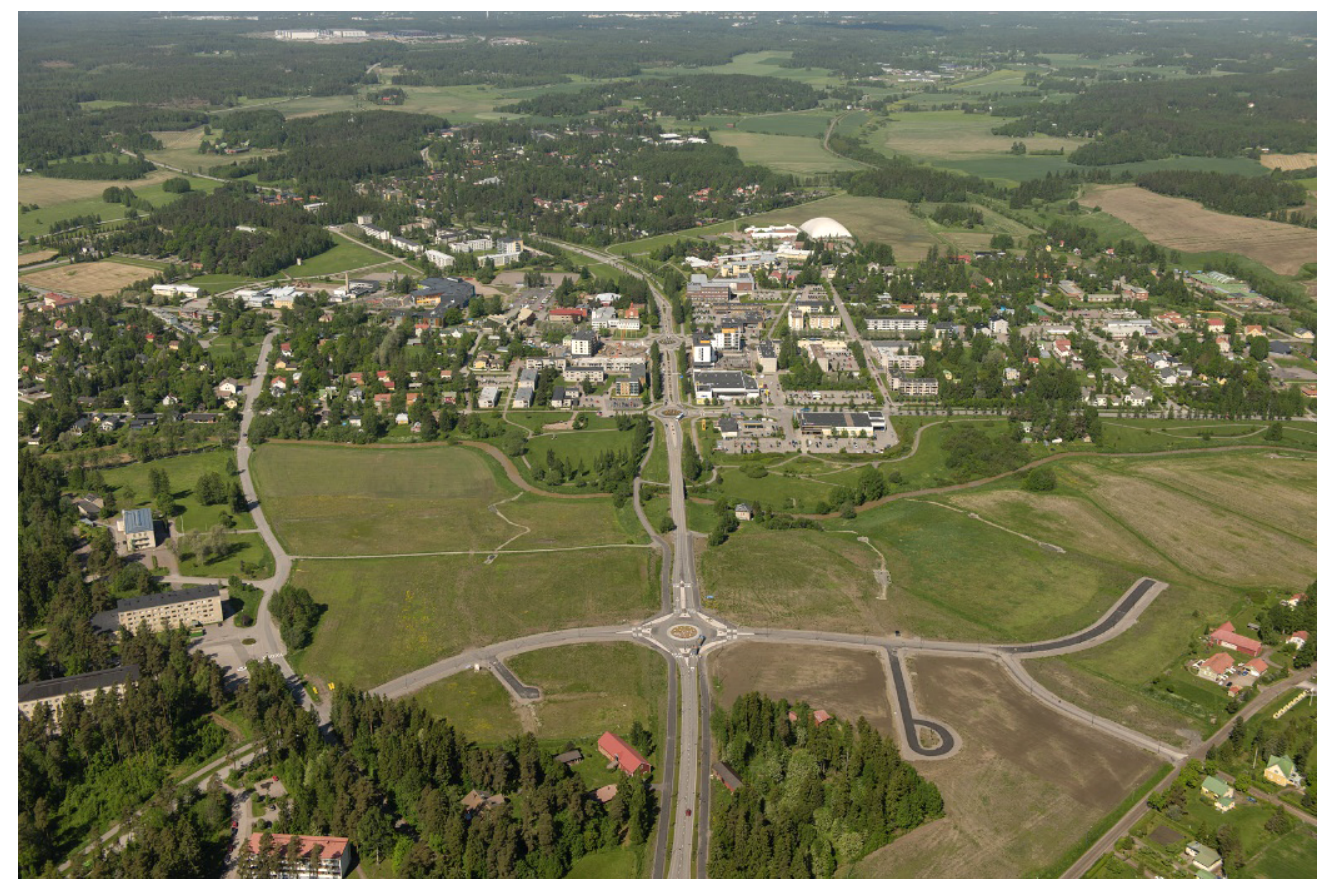

Figure 1. Areal photo of Nikkilä. Copyright: Municipality of Sipoo, Ilmakuva Vallas Oy/Hannu Vallas. Used with permission. 

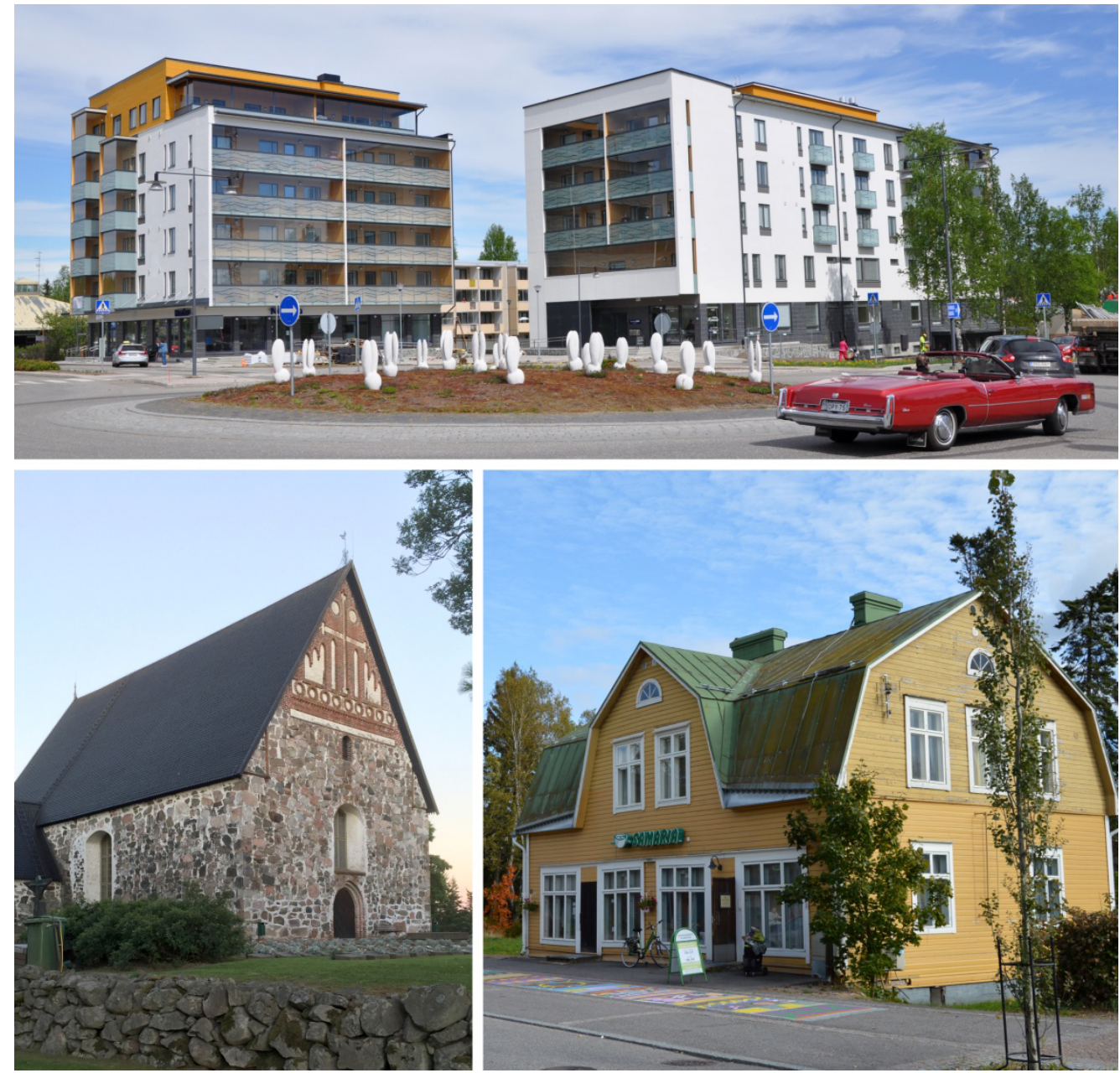

Figure 2. Old and new buildings in Nikkilä. Above: New apartment buildings in the heart of Nikkilä. Copyright: Suvi Suovaara and Municipality of Sipoo; below: the old mediaeval stone church from the fifteenth century (picture by the author) and old wooden house in the main street of Nikkilä (Iso Kylätie), Copyright: Municipality of Sipoo. Used with permission.

The questionnaire was promoted in various ways: first, the preliminary version of the questionnaire was tested in an event for local residents of Nikkilä. Then, the project was launched and local media were informed, and the URL address of the questionnaire was shared in social media (e.g., the Facebook page of the municipality). Also, Facebook marketing targeted for users living in Sipoo was used to reach the respondents.

Table 1 shows the overview of respondents of the questionnaire. Surprisingly, although the map questionnaire was promoted in Sipoo, altogether 38\% of the respondents came from outside the municipality, and only $32 \%$ were local residents of Sipoo. It is evident that many former residents answered the questionnaire. The age of the respondents centres around age groups from 26 to 65 . Younger and older respondents were in the minority. Women were more active in responding (62\%) than men (38\%).

The map questionnaire comprised four parts: 1) evaluating old buildings (built cultural heritage) as shown in Figure $3 ; 2$ ) adding personally important buildings on the map; 3) evaluating culturally important landscape areas; and 4) sharing memories and stories about Nikkilä.
This article focuses on the built cultural heritage (parts 1 and 2) and people's place-based memories (part 4).

Table 1. Overview of the PPGIS respondents.

\begin{tabular}{ll}
\hline & Percentage (\%) \\
\hline $\begin{array}{l}\text { Gender } \\
\text { Male }\end{array}$ \\
Female & $38 \%$ \\
\hline Age & $62 \%$ \\
under 18 & \\
$19-25$ & $1 \%$ \\
$26-35$ & $9 \%$ \\
$36-45$ & $18 \%$ \\
$46-55$ & $20 \%$ \\
$56-65$ & $26 \%$ \\
$66-75$ & $18 \%$ \\
over 75 & $6 \%$ \\
\hline Place of residence & $1 \%$ \\
Nikkilä & \\
Other place in Sipoo & $32 \%$ \\
Somewhere else & $30 \%$ \\
\hline
\end{tabular}




\section{COGITATIO}

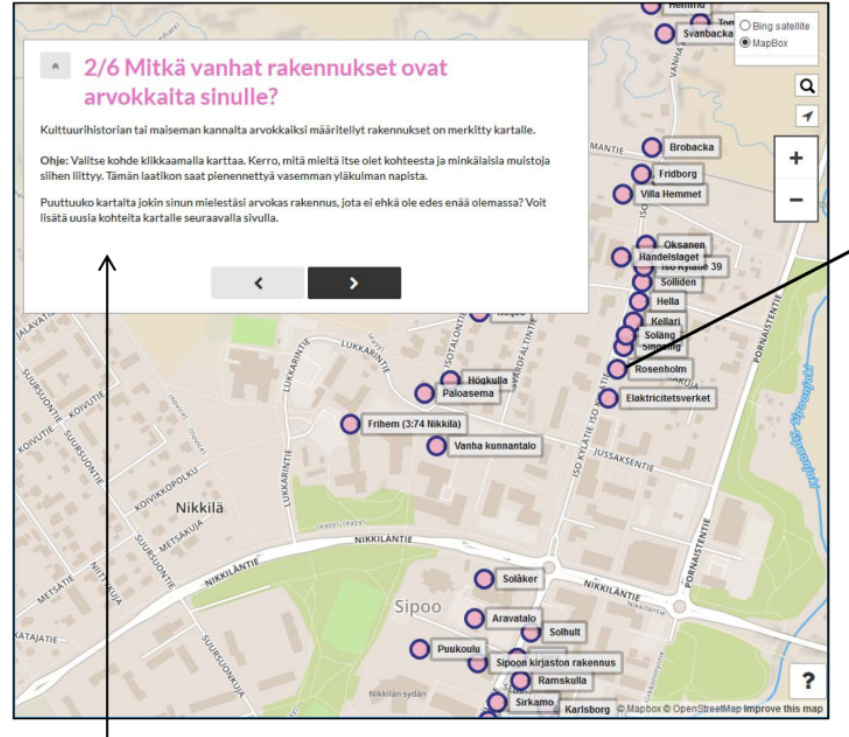

Question 2:

Which old buildings are imporant to you?

Buildings that have been identified as valuable based on the cultural history or landscape are shown on the map.

Instruction: Choose the object by clicking on the map. Tell, what do you think about the building and what kind of memories do you have of it.

Is a building valuable to you, maybe even if demolished, missing on the map? On the next page, you can add new objects to the map on.

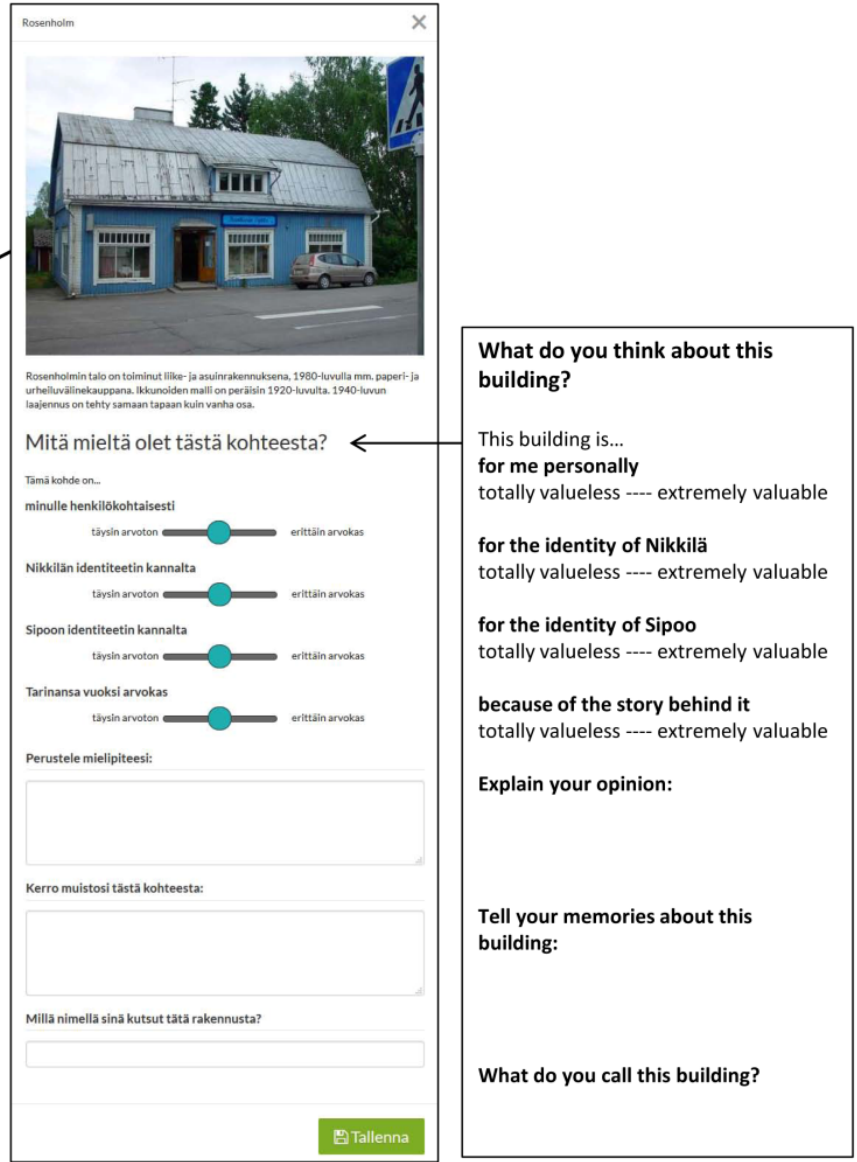

Figure 3. A screen of Nikkilä Memories map questionnaire. Copyright: Municipality of Sipoo and Mapita Oy. Used with permission.

The screenshot (Figure 3) represents the part of the questionnaire where the respondent was able to evaluate the cultural heritage buildings and to share memories about the building. The data was used to assess how people's evaluations differ from the experts' evaluation of the built heritage. Apart from that, memories linked to the buildings were analysed to understand the meaning of the buildings.

\subsection{Social Media Monitoring}

Social media were used as a crowdsourcing tool by encouraging people to share their memories from Nikkilä with hashtag \#muistojennikkilä on Instagram, Twitter and Facebook. An Instagram profile called Nikkilä Memories was opened in April 2016 to facilitate crowdsourcing. With that profile, the author forwarded memories collected with the map questionnaire to inspire people to share their memories. ViidakkoMonitor, a social media monitoring tool developed by a Finnish IT company, Koodiviidakko Oy, was used for following the hashtag \#muistojennikkilä in all the channels from June 2016 to June 2017.

During the time from June 2016 to June 2017, people shared in total 228 posts with the hashtag. Posts were manually classified by their content, and, as a result, $28 \%$ of the posts were related to landscapes, $22 \%$ to buildings, $19 \%$ to events organized in Nikkilä and $12 \%$ to art or culture.

Instagram was the primary tool, with 191 posts, and it appeared to complement the PPGIS data in an essential way by providing visual representations of peoples' place-based experiences. The major flaw with the social media data was that it did not contain any geodata. Apart from that, it is evident that only a small group of active residents were posting content.

\subsection{Observation of a Local Facebook Group}

A local Facebook group called 'Old buildings in Sipoo' (Sipoon vanhat rakennukset-Gamla byggnader i Sibbo) was observed to find out if people shared their memories or discussed the built cultural heritage on Facebook. The observation was executed manually during a two-month period in spring 2016.

'Old buildings in Sipoo' is a closed Facebook group with more than 800 members. In Facebook, anyone can find closed groups and see their members but only members can see posts in that group (Facebook, 2017). Closed or secret groups cannot be crawled with social media does not allow downloading of data from the groups. monitors and, to protect the privacy of users, Facebook 
Ensuring the privacy of social media users is recognised as a critical issue in social media research. Even if the data is publicly available, it does not mean that it can be used without considering privacy protection. On the contrary, Zimmer (2010) argues that 'privacy and anonymity do not disappear simply because subjects participate in online social networks; rather, they become even more important'.

In this case study, the observation of the group was agreed upon in a discussion with the group moderators. Furthermore, the researcher posted a message to the group describing how the observation was done. It was emphasised that no personal information (names or quotes) would be published without asking for permission. Observation was done afterwards by manually browsing the group news feed.

\subsection{Map Analysis}

The crowdsourcing data was manually analysed with a qualitative approach. The data collected, i.e., results from the map questionnaire and posts from social media, were brought together on one map. Combining all the different data sources was laborious, largely because the social media posts were not geotagged, and the loca- tions of the posts were marked manually on the map if it was possible to identify the place. The locations of the images and posts were not recognisable in all posts, and, thus, it was impossible to show all the data on the map: altogether, only 68 out of 191 Instagram posts (i.e., 36\%) were included in the map analysis. Despite this, it seems that social media do support and complement crowdsourcing with the questionnaire: for example, some demolished buildings (e.g., the old bus station in Figure 5, gas station and milk central) are mentioned in both forms of data, but pictures of those buildings are shared only in social media.

The social media also tell stories not available in the questionnaire data. For example, buildings and sites that are currently under construction are emphasised in social media even if the buildings have not been recognised as important. This naturally indicates the importance of the local environment and the ongoing change in the town.

The conjunctive map analysis revealed various findings (numbers indicate the locations on the map in Figure 4):

- Demolished buildings (1) are part of the cultural heritage of Nikkilä. These buildings are mentioned

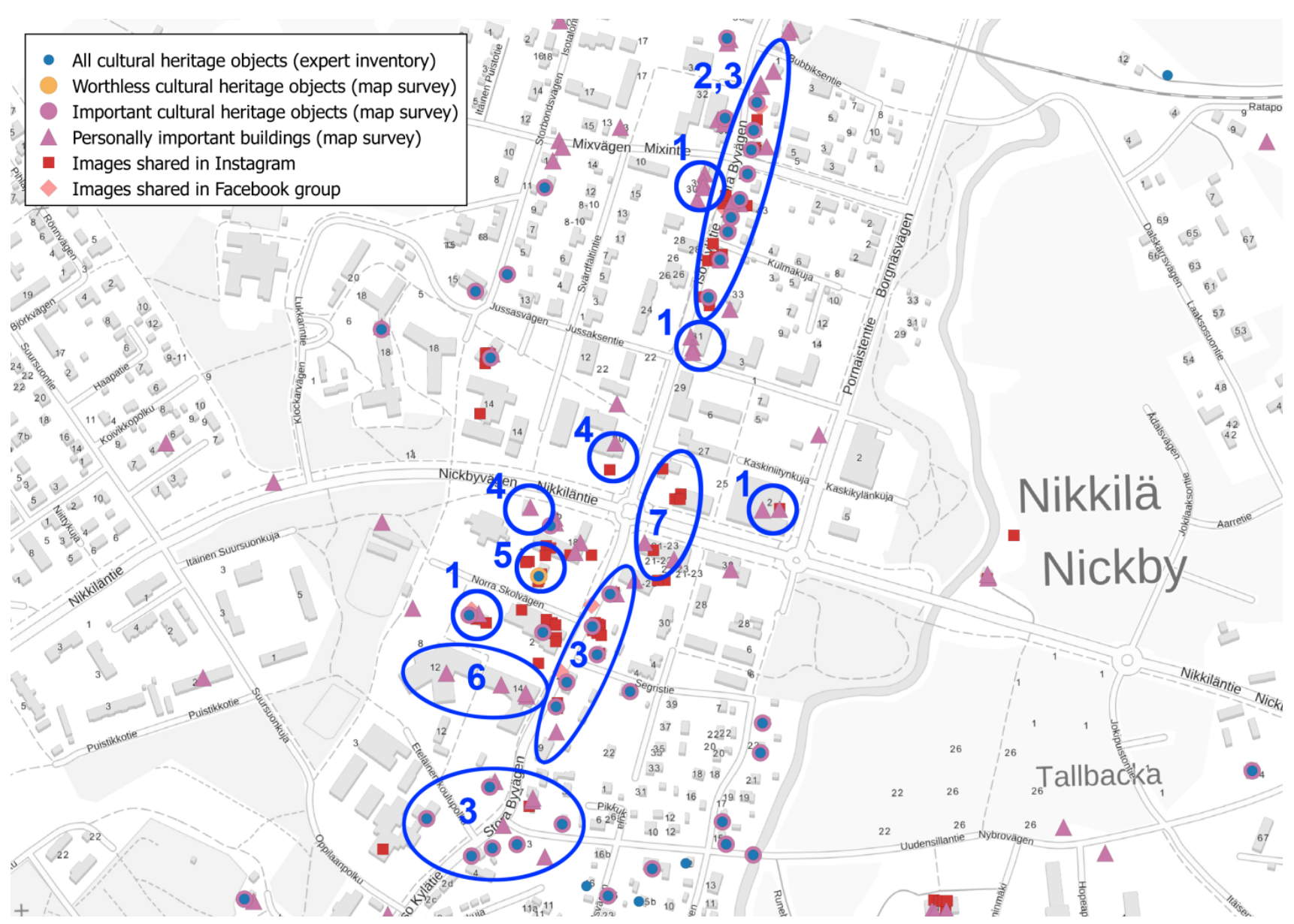

Figure 4. Thematic map of crowdsourced data from map questionnaire and Instagram. Copyright: Map background: National Land Survey of Finland, 10 November 2017. 
in both the questionnaire and social media, but pictures of these are shared only in social media.

- Buildings that are evaluated as important in the PPGIS data also get attention in social media (such as the old wooden houses on Iso Kylätie) (2).

- In the centre of Nikkilä, most of the cultural heritage objects evaluated as valuable by experts in the cultural heritage inventory of Sipoo are also valued as personally important by the respondents (3).

- Some personally valued buildings are not considered important in the cultural heritage inventory (for example, an old barn and a restaurant from the 70s) (4).

- There is only one cultural heritage object, an old apartment block from the 1940s, that was evaluated as invaluable in PPGIS (5). However, this building was recognised many times in social media, because of an art work: a mural painted on the walls of the building.

- Meeting places such as schools, grocery stores and restaurants are often evaluated as personally important buildings in the PPGIS data (6).

- In social media, buildings and sites that are currently under construction are emphasised even if the buildings have not been recognised as important in PPGIS (7).

\section{Results from the Case Study Nikkilä Memories}

The crowdsourcing model used in the case study combined different data sources: map questionnaire, Instagram and Twitter posts and observation of a selforganized Facebook group. The data sources appeared to be powerful sources of three different types of local knowledge: PPGIS provided knowledge for comparison of expert and non-expert values and place-based memories; social media (especially Instagram) provided a tool for gathering and sharing visual representations of placebased experiences; the self-organized Facebook group appeared to be a tool for collective memory and knowledge building. In the following sections, the results are discussed in detail.

\subsection{Functionality of the Crowdsourcing Model}

In this article, the main research focus is on the crowdsourcing model and how functional the combination of PPGIS and social media crowdsourcing was in this case. The results indicate that this kind of multi-method crowdsourcing is beneficial but laborious to implement and analyse. It is evident that the methods complement each other; with PPGIS, it was possible to evaluate the importance of old buildings and collect textual place-based memories. Social media, especially Instagram, on the other hand, provided a large amount of visual representations of people's experiences from Nikkilä. However, it seems difficult to capture the authentic experience from the Instagram posts. In some cases, users describe their feelings about the places but often the interpretation remains open. Apart from that, only a fraction of the images were geotagged and the monitoring tool that was used did not collect location data. Thus, the Instagram data presented on the analysis map was geotagged manually by the researcher. To do so, it was necessary to be very familiar with the place.

The Instagram data consisted mostly of instant experiences rather than memories. Exceptions were a couple of historical images, one representing the old bus station (Figure 5) and a landscape photo from the beginning of
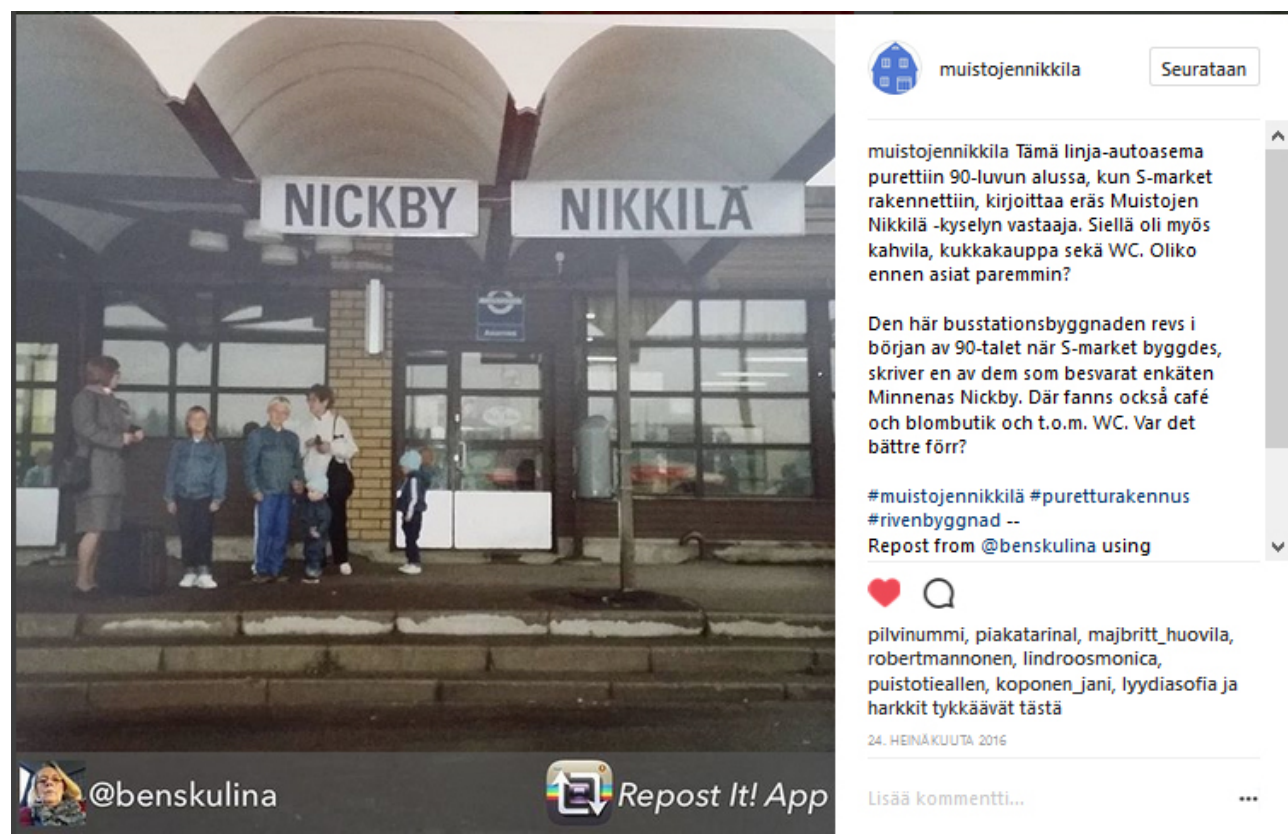

Figure 5. Nikkilä bus station, image shared on Instagram. Copyright: Benita Christina Lipponen. Used with permission. 
the twentieth century. Naturally, it requires more motivation to post an old picture to Instagram since the tool is designed for posting images taken with mobile device.

\subsection{Comparison between Local Knowledge and Expert Knowledge}

The map analysis (Figure 4) provides an insight into residents' views in relation to expert knowledge by visualising the cultural heritage buildings identified by experts and buildings valued by residents in parallel. It shows that, in the centre of Nikkilä, almost all the cultural heritage buildings defined by the authorities are appreciated also by the respondents of the questionnaire. Only one building in the centre of Nikkilä, a former apartment building built in the 1940s (Figure 6), was evaluated negatively by the respondents due to its bad condition and 'ugly' appearance. The results indicate a reasonable level of consensus about the values of the built cultural heritage between the experts and local people. Yet, there are buildings that were reported as valuable personally for the respondents, but are not recognised as culturally valuable by the authorities. These buildings are, for example, schools, stores, homes and locations of buildings that have been demolished, such as the old bus station of Nikkilä, two gas stations and kiosks where kids used to buy candies.

Pictures of buildings that were considered valuable in the questionnaire were also shared on social media. Hence, it seems that social media complement and confirm the results from the questionnaire. On Instagram, people shared pictures of personally important buildings, but also new buildings that were under construction in the centre of Nikkilä. In this way, the change of the physical environment is documented on social media.
5.3. The Value of Place-Based Memories: Revealing the Intangible Cultural Heritage

Based on qualitative analysis of this heterogeneous data set, it was possible to find out how people value cultural heritage buildings in Nikkilä. Furthermore, based on people's memories and experiences presented in the PPGIS and social media, it was possible to understand the reasons why these buildings are valued. For example, many childhood memories from the mid-twentieth century were reported. This rich source of memories and experiences can be seen as a representation of intangible cultural heritage: the data reveals the local history of Nikkilä as experienced by local people and also reveals places that are currently provoking new memories.

The map questionnaire data, especially the memories mapped to the old wooden houses along the main street, Iso Kylätie, reveal the intangible aspects of cultural heritage. A lot of memories are related to shops and services that used to operate in the wooden houses along the main street of the village, Iso Kylätie. For example, these quotes describe the memories related to shops and services (free translations by the author):

As a child, I went shopping in "Ässä" many times. I have danced until the early hours in "Kellari".

Was it here where Lagerqvist was selling cheese? At some point there was an electrical shop on one side of the building also.

There was Broström's car spare part shop in this building. Earlier he had a gas station. There was everything you needed.

Rosenholm's was a legendary shop where you could buy everything you needed. The smell in the shop was extremely fine and service was always good and
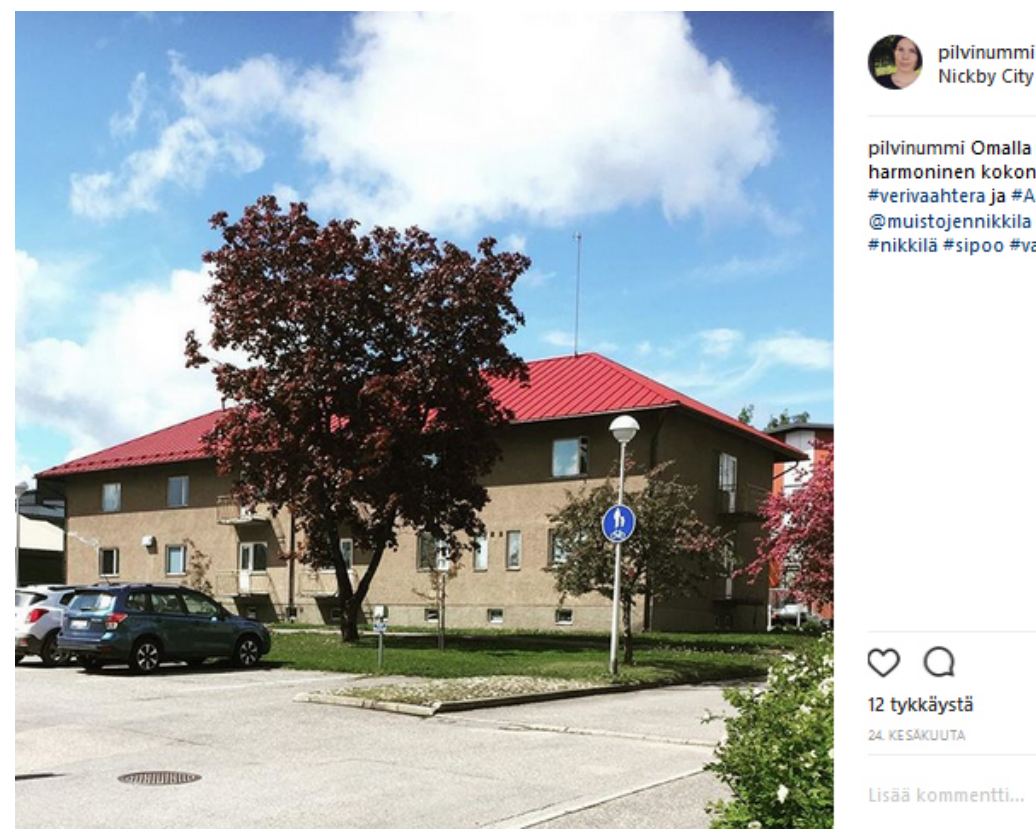

pilvinummi Omalla tavallaan kaunis ja harmoninen kokonaisuus, vanha \#verivaahtera ja \#Aravatalo. @muistojennikkila \#muistojennikkilà \#nikkilä \#sipoo \#vanhatrakennukset

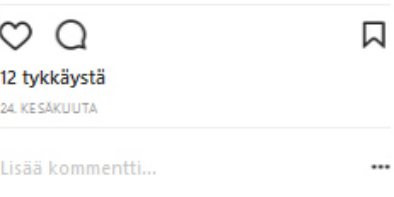

Figure 6. An old apartment building called 'Aravatalo' in the centre of Nikkilä was evaluated as worthless. Copyright: author. 
friendly! My mother used to work there as an assistant and that felt extremely fabulous as a child.

This is where we used to shop at the beginning of the 1950s when we were riding bikes. Rosenholm had everything, all the possible spare parts for bicycles. Books, bicycles, mopeds, LPs, fabrics, threads and nails etc. Here I bought my Billnäs spanner to be able to change tyres myself.

Some of these old buildings still exist and new local services, like a café, a decoration shop, a car service and a flea market, operate in the houses. Based on the results of the crowdsourcing, it is evident that this local 'shopping street' is an important part of Nikkilä's intangible cultural heritage, and developing it further as an active part of Nikkilä would support the local identity.

It is not surprising that a local shopping street with a variety of services and shops is a central part of people's memories. Zukin (2012) has pointed out in a case study in Amsterdam that local shopping streets shape the intangible cultural heritage and store collective memory. She emphasises that modern consumer culture and globalised businesses are a threat to these streets, and, therefore, official protection is needed. In Nikkilä, the intangible culture of the local businesses and old buildings on the main street is in danger of extinction.

\subsection{Building a Collective Memory in Self-Organized Facebook Group}

The local self-organized Facebook group 'Old buildings in Sipoo' appeared to be a good source of local history and a place for shaping a collective memory; people seemed to be eager to share information, memories and pieces of local history there. It is quite obvious that in a local group specialising in old buildings, people discuss the history of buildings and places, and, thus, they build a collective memory together.

Sharing memories in the Facebook group often started when a picture of an old building or a historical picture was posted to the group. This makes it challenging or even impossible to automatically monitor memories in social media. In this case, discussions in the Facebook group were observed manually by following the group as a member. In fact, on the record, there are no social media monitoring tools that can be used for monitoring closed Facebook groups.

One example of an image that evoked memories is the picture of old wooden houses on the main street of Nikkilä (Iso Kylätie) (Figure 7). The original post only consists of the year (presumably the year the image was taken) and the photograph. Inspired by the photo, people started to discuss what kind of shops there have been in the buildings and what they had bought (or wished to buy) there. For example, in this case the discussion starts with a memory of a book shop and continues with the items they were selling (freely translated by the author):
There was Rosenholm's book and gift store in the blue house. (Member 1)

Rosenholm had much more: toys, fireworks, fabrics, yarns, sewing material, bikes and repair and spare part service for bikes and mopeds. (Member 2)

We had our eyes on the toys in that gable window. (Member 1)

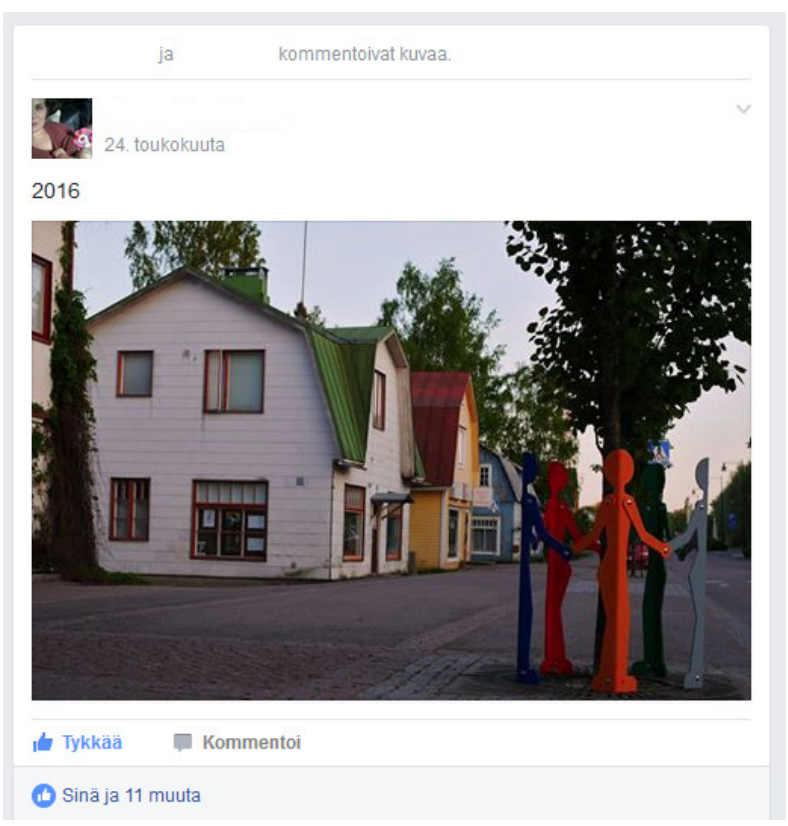

Figure 7. Screenshot from Facebook group 'Old buildings in Sipoo'. An image that evoked memories. Copyright of the photograph: Jenna Seppänen. Used with permission.

This kind of information describing the use of the building is useful for cultural history inventories; it describes the intangible part of cultural history that is often missing. Apart from that, these results suggest that people's memories should be a part of the knowledge base of urban planning. Memories and stories are easy to empathise with, and it would help planners to see the place through other people's eyes and to better understand the intangible cultural heritage.

As on Instagram, the buildings that were commented on Facebook are mostly the same as those that were evaluated as important in PPGIS. The difference on Facebook is that people also share their memories and discuss the local history. From a crowdsourcing perspective, it is disappointing that such data is not open to be used in urban planning.

\subsection{Crowdsourcing Data-Benefits and Challenges for Planning Practices}

The results show how crowdsourcing with different tools provides different kinds of data. All the tools used in the crowdsourcing have their advantages and flaws. The main findings are presented in Table 2. 
Table 2. Comparison of crowdsourcing methods.

\begin{tabular}{llll}
\hline & PPGIS & Instagram & Facebook group \\
\hline Data & 186 respondents & $\begin{array}{l}\text { 191 posts shared with } \\
\text { hashtag \#muistojennikkilä }\end{array}$ & $\begin{array}{l}\text { 13 discussion threads related to } \\
\text { built cultural heritage in Nikkilä }\end{array}$ \\
\hline Users/respondents & $\begin{array}{l}\text { Residents of Nikkilä, other } \\
\text { parts of Sipoo or former } \\
\text { residents of Nikkilä }\end{array}$ & $\begin{array}{l}126 \text { followers, active users } \\
\text { (who post images) are local } \\
\text { residents from Nikkilä }\end{array}$ & $\begin{array}{l}\text { Local residents interested in } \\
\text { old buildings in Sipoo }\end{array}$ \\
\hline Benefits & $\begin{array}{l}\text { Geotagged data } \\
\text { Comparison of experts' } \\
\text { and residents' viewpoints }\end{array}$ & $\begin{array}{l}\text { Visual representations } \\
\text { complement PPGIS data }\end{array}$ & $\begin{array}{l}\text { Enables building a } \\
\text { collective memory }\end{array}$ \\
\hline Challenges & $\begin{array}{l}\text { Laborious analysis: GIS } \\
\text { is not designed for } \\
\text { qualitative content } \\
\text { analysis }\end{array}$ & $\begin{array}{l}\text { Availability of the data: collecting } \\
\text { data needs a monitoring tool, } \\
\text { the tool does not collect } \\
\text { geodata, geo-locating the }\end{array}$ & $\begin{array}{l}\text { Availability of the data: it is not } \\
\text { allowed to download data } \\
\text { from a closed Facebook group }\end{array}$ \\
& & $\begin{array}{l}\text { posts requires extensive } \\
\text { familiarity with the place }\end{array}$ & \\
\hline
\end{tabular}

As mentioned before, analysing the heterogeneous crowdsourcing data was laborious. Three main challenges were found during the analysis process: first, processing the qualitative GIS data from the questionnaire is not a straightforward process; GIS applications are not designed for qualitative analysis. Second, social media data was not geotagged. Since June 2016, Instagram does not provide an open API that would allow a researcher to crawl and download user-generated data. Therefore, to be able to perform a comprehensive analysis on the map, social media data was manually geotagged. Third, planners are still used to report-based practices. It became evident in the analysis phase that planners wanted the PPGIS data to be reported as a document where each building with the memories related to it is presented separately. The other option would have been to develop a map tool that combines all crowdsourcing data on one interactive map. This observation is in line with Eräranta and Staffans (2015), who argue that urban planning is still a strongly report-based activity. Therefore, integrating crowdsourcing into urban planning requires new data-oriented planning practices instead of working with static reports. In fact, this is crucial, as in practice it is impossible to publish usergenerated social media data as a report document due to the copyrights.

\subsection{The Reflection to the Planning of Nikkilä}

In the development plan of Nikkilä (Municipality of Sipoo, 2016), the planners of Sipoo analysed this information and translated it to alignments that guide future detailed planning. In that plan, it was, for example, identified that old milieus (especially the old wooden houses in Nikkilä) are not only dear to the residents, but also cornerstones of the identity of Nikkilä. Thus, it was aligned in the development plan that architectural heritage should be taken as a starting point when developing new build- ing (Municipality of Sipoo, 2016). This indicates that, in this case, buildings significant to participants should be maintained, and the new building should be fitted to the cultural heritage. However, it is mentioned in the development plan that the characteristics of traditional building can also be expressed by contemporary architecture. This means that the aim is to develop a townscape that contains different architectural layers that reflect the building period: old buildings with traditional style are preserved and new buildings with contemporary architecture complement the cultural heritage.

Currently, an outline plan and several detailed plans for the Nikkilä area are in the making. In the outline plan, the planners generated user profiles that represent different kinds of residents in Nikkilä. These profiles are then used for evaluating planning solutions. The planners also mentioned that the data can be used as background information for different future planning projects. The aim is to continue this study with a followup phase to find out how the data are used in these ongoing planning projects.

The analysis presented in this article, produced by the researcher, provides knowledge for the outline planning process of Nikkilä. It provides an interpretation of the sociocultural heritage of Nikkilä, a presentation that can and should be considered when evaluating the planning solutions. Especially considering how commercial services are developed and where are they located in the city structure is an important question. Also, how will traffic flows affect the old shopping street of Nikkilä: does it help business to flourish or not?

\section{Discussion}

Regardless of the encouraging results, this approach has several shortcomings in relation to representativeness of the participants, the useability of the PPGIS questionnaire, availability of social media data, difficulties in 
analysing heterogeneous data sets and limited usefulness of the results for urban planning.

The limitations of the PPGIS method relates to the representativeness of the participants. It is evident that the selection of tools using social media and internet as a primary marketing channel ended up with a result where respondents do not represent all age groups. Especially older respondents (over 66 years) are underrepresented, but also younger age groups (under 25 years) are missing based on the questionnaire results. Considering the number of residents in Nikkilä, the PPGIS method provided a relatively good number of respondents (in total, 186). However, in order to gather a comprehensive data set for evaluating the value of the old buildings, a larger respondent group would have been needed. Also, it became evident that there were useability problems with the questionnaire; some respondents claimed that it was too difficult to use the map and evaluating the old buildings was burdensome.

The PPGIS method was designed primarily for comparison of local and expert opinions. It is probable that presenting the cultural heritage objects valued by experts as a basis for the evaluation had an influence on the responses. In the questionnaire, respondents were asked to evaluate buildings considered valuable by the experts, but, after this stage, they were given a possibility to add personally important buildings on the map. Altogether, 106 personally important buildings were mapped, of which one proportion was old buildings already demolished, one proportion included some buildings that were presented in the expert evaluation, and one proportion were buildings considered important by respondents but not valued by the experts. If the goal of the case study would have been only to identify personally important buildings, it would have been better to leave out the expert evaluation data and let the respondents map important buildings from the scratch, which would probably have ended up as a different result.

One significant bias identified in the quality of the memories was that negative memories were missing. There were no memories, for example, about war, unemployment or poverty, even if, in the history of Nikkilä, there are relations to Finnish military history. The reason for this bias is not clear; maybe the questionnaire could have been designed differently to encourage looking back to negative things as well.

As mentioned in the results, the heterogeneous data set was laborious to analyse as the crowdsourcing model was new and no existing analysis tools were available. The map analysis required manual mapping of the social media data, and the qualitative analysis of PPGIS data was done manually as well.

For urban planning, this method provided a new type of knowledge, and, beforehand, it wasn't clear how to use the data. During this study, it became evident that the usefulness of the data is limited, and that planners prefer to use reports instead of raw data in planning. In the future, the aim is to study further how the data and results of this study will be used in the planning of Nikkilä.

With the use of social media, the problems relate to the copyright and use right issues. For example, it is not allowed to publish images shared on Instagram without owner's permission, and, thus, using the shared images in planning is not straightforward. Additionally, downloading data from closed Facebook groups is against Facebook's rules, and, therefore, the value of the collective memories generated on Facebook remains limited for urban planning. Furthermore, the images shared on Instagram were actually rather representing instant experiences than place-based memories. It seems to be difficult to facilitate social media users to answer specific questions. Nevertheless, it is evident that facilitating the content production on Instagram affected the users' activities; selected images were shared further (reposted) by the Nikkilä Memories profile, and, as users consider reposting of their content as a reward, that may have had an effect on the content people share.

\section{Conclusions}

This study contributes to research by developing and testing a crowdsourcing method that combines PPGIS and social media. In the case study, a rarely used type of local knowledge-place-based memories-is applied to the planning of a small, but growing and densifying town that has cultural heritage values. Experiences from the case study are especially relevant in cases where a culturally sensitive planning approach is chosen. Furthermore, results provide knowledge for further development of the crowdsourcing model and methods that aim to compare local knowledge and expert knowledge.

The results indicate that crowdsourcing is a functional tool for gathering place-based memories and revealing local people's values related to old buildings and intangible cultural heritage, and comparing local knowledge with expert knowledge. Furthermore, it is apparent that social media data can complement other forms of data such as PPGIS data. Similar findings have been identified in other studies as well (e.g., Heikinheimo et al., 2017). In this study, social media data complemented PPGIS data with visual representations of memories and experiences, and provided local people a place for shaping collective memories.

As Pánek and Benediktsson (2017) argue, systems that support participatory planning can help to bridge the gap between planners and the public. In this case, the gap between expert knowledge and local knowledge was bridged with a crowdsourcing model in three different ways. First, local people's values in relation to built cultural heritage were studied by comparing experts' and citizens' evaluations of old buildings in Nikkilä. Second, the intangible dimensions of Nikkilä's cultural heritage were identified to help planners understand the identity of Nikkilä. Third, by developing resident profiles to be used for evaluating planning solutions, the planners used the data for understanding local viewpoints. 
This study revealed several challenges for using a multi-method crowdsourcing model in collaborative planning. As mentioned earlier, participatory planning is an interactive process (Healey, 1997). It is arguable that the process of Nikkilä Memories has some interactive elements, and especially the use of social media added interaction to the process. However, using the PPGIS tool is mostly non-interactive in the sense that it doesn't create a dialogue between people and planners. Thus, from the participatory planning perspective, it is relevant to continue the process with interactive planning methods.

Collaborative knowledge building that aims at shared understanding is a central element of participatory urban planning (Healey, 1999). Planning theories do not provide tools for knowledge building in practice, and, therefore, empirical studies that solve the challenges of collecting, analysing and managing user-generated data are needed. In this study, a closed Facebook group appeared to be a functional tool for knowledge building, as people were sharing and discussing their memories there and created collective memories. However, there is still a need for new tools to share the crowdsourcing results with a wider audience.

As Eräranta and Staffans (2015) argue, it seems that urban planning still is a largely report-based activity. It became evident during the crowdsourcing project that planners prefer static reports instead of using data with interactive applications. An interactive web map was produced but still the planners required the results as a report. These findings underline the need to develop dataoriented practices for urban planning. Moreover, there is a need to develop a useable and efficient analysis method for heterogeneous user-generated data. Especially the use of social media data adds challenges to data analysis. From the crowdsourcing perspective, it is also relevant to consider methods that allow local people not only to participate as knowledge producers, but also to engage people in idea generation, as argued by Brabham (2009).

\section{Acknowledgements}

I want to thank all the local people in Sipoo who took part in Nikkilä Memories project by providing their memories and values in the crowdsourcing. Without active citizens this project would not have been successful. The municipality of Sipoo has provided funding for the map survey tool used in the case study. Many thanks to general planning architect Eveliina Harsia and urban planner Aino Kuusimäki for making this project possible and cooperation in the project. Also, many thanks to Maarit Kahila and Anna Broberg from Mapita Ltd who assisted the project team in developing the map questionnaire.

\section{Conflict of Interests}

The researcher has worked as a town planning architect in the Municipality of Sipoo.

\section{References}

Aiello, L. M., Schifanella, R., Quercia, D., \& Aletta, F. (2016). Chatty maps: Constructing sound maps of urban areas from social media data. Royal Society Open Science, 3(3), 1-19.

Bianchini, F., \& Ghilardi, L. (2007). Thinking culturally about place. Place Branding and Public Diplomacy, 3(4), 280-286.

Brabham, D. C. (2009). Crowdsourcing the public participation process for planning projects. Planning Theory, 8(3), 242-262. https://doi.org/10.1177/ 1473095209104824

Brown, G. (2015). Engaging the wisdom of crowds and public judgement for land use planning using public participation geographic information systems. Australian Planner, 52(3), 199-209. https://doi.org/ 10.1080/07293682.2015.1034147

Campagna, M. (2014). The geographic turn in social media: Opportunities for spatial planning and geodesign. In B. Murgante, S. Misra, A. M. A. C. Rocha, C. M. Torre, J. G. Rocha, M. I. Falcão, . . . O. Gervasi (Eds.), Computational science and its applicationsICCSA 2014 (pp. 598-610). Berlin: Springer.

Campagna, M., Floris, R., Massa, P., Girsheva, A., \& Ivanov, K. (2015). The role of social media geographic information (SMGI) in spatial planning. In S. Geertman, J. Ferreira Jr., R. Goodspeed \& J. Stillwell (Eds.), Planning support systems and smart cities: Lecture notes in geoinformation and cartography (pp. 41-60). Basel: Springer International Publishing Switzerland.

Cranshaw, J., Schwartz, R., Hong, J., \& Sadeh, N. (2012). The Livehoods project: Utilizing social media to understand the dynamics of a city. In Proceedings of the International AAAI Conference on Web and Social Media (pp. 58-65). Dublin: AAAI Press.

Dunkel, A. (2015). Visualizing the perceived environment using crowdsourced photo geodata. Landscape Architecture and Environmental Planning. Special Issue: Critical Approaches to Landscape Visualization, 142, 173-186.

Elwood, S., Goodchild, M. F., \& Sui, D. Z. (2012). Researching Volunteered Geographic Information: Spatial data, geographic research, and new social practice. Annals of the Association of American Geographers, 102(3), 571-590, https://doi.org/10.1080/ 00045608.2011 .595657

Eräranta, S., \& Staffans, A. (2015). From situation awareness to smart city planning and decision making. Paper presented at the 14th International Conference on Computers in Urban Planning and Urban Management, July 7-10, 2015, Cambridge, MA.

Facebook. (2017). What are the privacy settings for groups? Facebook Help Center. Retrieved from www.facebook.com

Finlex. (1999). Maankäyttö- ja rakennuslaki [Land Use and Building Act]. Retrieved from www.finlex.fi/fi/ laki/ajantasa/1999/19990132 
Frias-Martinez, V., \& Frias-Martinez, E. (2014). Spectral clustering for sensing urban land use using Twitter activity. Engineering Applications of Artificial Intelligence, 35, 237-245. https://doi.org/10.1016/ j.engappai.2014.06.019

Healey, P. (1997). Collaborative planning. Shaping places in fragmented societies. Hampshire and London: Macmillan Press.

Healey, P. (1999). Institutionalist analysis, communicative planning, and shaping places. Journal of Planning Education and Research, 19, 111-121.

Heikinheimo, V., Di Minin, E., Tenkanen, H., Hausmann, A., Erkkonen, J., \& Toivonen, T. (2017). Usergenerated geographic information for visitor monitoring in a national park: A comparison of social media data and visitor survey. ISPRS International Journal of Geo-Information, 6(3), 85; https://doi.org/ 10.3390/ijgi6030085

Howe, J. (2006, June). The rise of crowdsourcing. Wired Magazine. Retrieved from www.wired.com

Hu, Y., Gao, S., Janowicz, K., Yu, B., Li, W., \& Prasad, S. (2015). Extracting and understanding urban areas of interest using geotagged photos. Computers, Environment and Urban Systems, 54, 240-254.

Kahila, M., \& Kyttä, M. (2008). SoftGIS as a bridge builder in collaborative urban planning. In S. Geertman \& J. Stillwell (Eds.), Planning support systems: Best practices and new methods. Springer.

Kahila-Tani, M., Broberg, A., Kyttä, M., \& Tyger, T. (2016). Let the citizens map-Public participation GIS as a planning support system in the Helsinki Master Plan process. Planning Practice \& Research, 31(2), 195-214.

Khan, G. (2015) Social media-based government explained: Utilization model, implementation scenarios, and relationships. In I. Boughzala, M. Janssen, \& S. Assar (Eds.), Case studies in e-government 2.0. Springer, Cham.

López-Aparicio, S., Vogt, M., Schneider, P., Kahila-Tani, M., \& Broberg, A. (2017). Public participation GIS for improving wood burning emissions from residential heating and urban environmental management. Journal of Environmental Management, 191, 179-188. https://doi.org/10.1016/j.jenvman.2017.01.018

López-Ornelas, E., \& Zaragoza, N. M. (2015). Social media participation: A narrative way to help urban planners. In G. Meiselwitz (Ed.), Social computing and social media, LNCS (Vol. 9182, pp. 48-54). Basel: Springer International Publishing Switzerland.

Mueller, J., Lu, H., Chirkin, A., Klein, B., \& Schmitt, G. (2018). Citizen design science: A strategy for crowd-creative urban design. Cities, 72(A), 181-188. https://doi.org/10.1016/j.cities.2017.08.018

Municipality of Sipoo. (2006). Sipoon kunnan kulttuuriympäristö- ja rakennusperintöselvitys [Inventory of cultural heritage in the Municipality of Sipoo]. Arkkitehtitoimisto Lehto Peltonen Valkama Oy, Ympäristötoimisto Oy.
Municipality of Sipoo. (2016). Nikkilän kehityskuva [The development plan for Nikkilä]. Nikkilä Nickby. Retrieved from www.nikkilanickby.fi

Nakatsu, R. T., Grossman, E. B., \& Charamblos, L. I. (2014). A taxonomy of crowdsourcing based on task complexity. Journal of Information Science, 40(6), 823-834. https://doi.org/10.1177/0165551514550140

Nielek, R., Ciastek, M., \& Kopeć, W. (2017). Emotions make cities live. Towards mapping emotions of older adults on urban space. Conference paper in WI '17, August 23-26, 2017, Leipzig, Germany.

Nummi, P. (2017). Social media data analysis in urban e-planning. International Journal of E-Planning Research, 6(4), 18-31.

Nummi, P., \& Tzoulas, T. (2015). Engaging citizens in cultural planning with a web map survey. Culture and Local Governance, 5(1/2), 161-173.

Official Statistics of Finland. (2017). Use of information and communications technology by individuals. Statistics Finland. Retrieved from www.stat.fi

Paldino, S., Bojic, I., Sobolevsky, S., Ratti, C., \& González, M. C. (2015). Urban magnetism through the lens of geo-tagged photography. EPJ Data Science, 4(5), $1-17$.

Pánek, J., \& Benediktsson, K. (2017). Emotional mapping and its participatory potential: Opinions about cycling conditions in Reykjavík, Iceland. Cities, 61, 65-73.

Quercia, D., Aiello, L. M., \& Schifanella, R. (2016). The emotional and chromatic layers of urban smells. In Proceedings of the 10th International AAAl Conference on Web and Social Media (ICWSM) (pp. 309-318). California, Palo Alto: AAAI Press.

Resch, B., Summa, A., Zeile, P., \& Strube, M. (2016) Citizen-centric urban planning through extracting emotion information from Twitter in an interdisciplinary space-time-linguistics algorithm. Urban Planning, 1(2), 114-127. https://doi.org/10.17645/ up.v1i2.617

Seltzer, E., \& Mahmoudi, D. (2012). Citizen participation, open innovation, and crowdsourcing: Challenges and opportunities for planning. Journal of Planning Literature, 28(1), 3-18. https://doi.org/ 10.1177/0885412212469112

Sykora, M., Robertson, C., Shankardass, K., Feick, R., Shaughnessy, K., Coates, B., ... Jackson, T. W. (2015). Stresscapes: Validating linkages between place and stress expression on social media. In I. Katakis, F. Schnitzler, T. Liebig, D. Gunopulos, K. Morik, G. Andrienko, \& S. Mannor (Eds.), Proceedings of the 2nd International Workshop on Mining Urban Data (pp. 80-84).

Tasse, D., \& Hong, J. I. (2014). Using social media data to understand cities. In P. Thakuriah, N. Tilahun, \& M. Zellner (Eds.), Proceedings of NSF Workshop on Big Data and Urban Informatics (pp. 64-79). Chicago: University of Illinois Press.

Van Herzele, A. (2004). Local knowledge in action. Valu- 
ing nonprofessional reasoning in the planning process. Journal of Planning Education and Research, 24, 197-212.

Yang, P., \& Ng, T. L. (2017). Gauging through the crowd: A crowd-sourcing approach to urban rainfall measurement and storm water modeling implications. Water Resources Research, 53(11), 9462-9478. https://doi.org/10.1002/2017WR020682

Zhou, X., \& Zhang, L. (2016). Crowdsourcing functions of the living city from Twitter and Foursquare data. Cartography and Geographic Information Science, 43(5), 393-404. https://doi.org/10.1080/ 15230406.2015.1128852

Zimmer, M. (2010). "But the data is already public": On the ethics of research in Facebook. Ethics and Information Technology, 12(4), 313-325.

Zukin, S. (2012). The social production of urban cultural heritage: Identity and ecosystem on an Amsterdam shopping street. City, Culture and Society, 3, 281-291.

\section{About the Author}

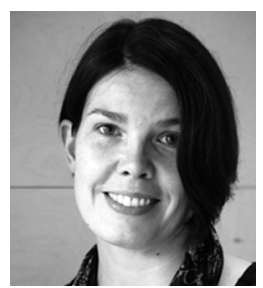

Pilvi Nummi (architect MSc) is a doctoral candidate in the Department of Built Environment, School of Engineering, at Aalto University (Finland). Her research interest is in e-Planning and e-Participation in urban and land-use planning, especially in the use of social media in participatory urban planning. Since year 2008, she has worked as a town planning architect in Finland. 